
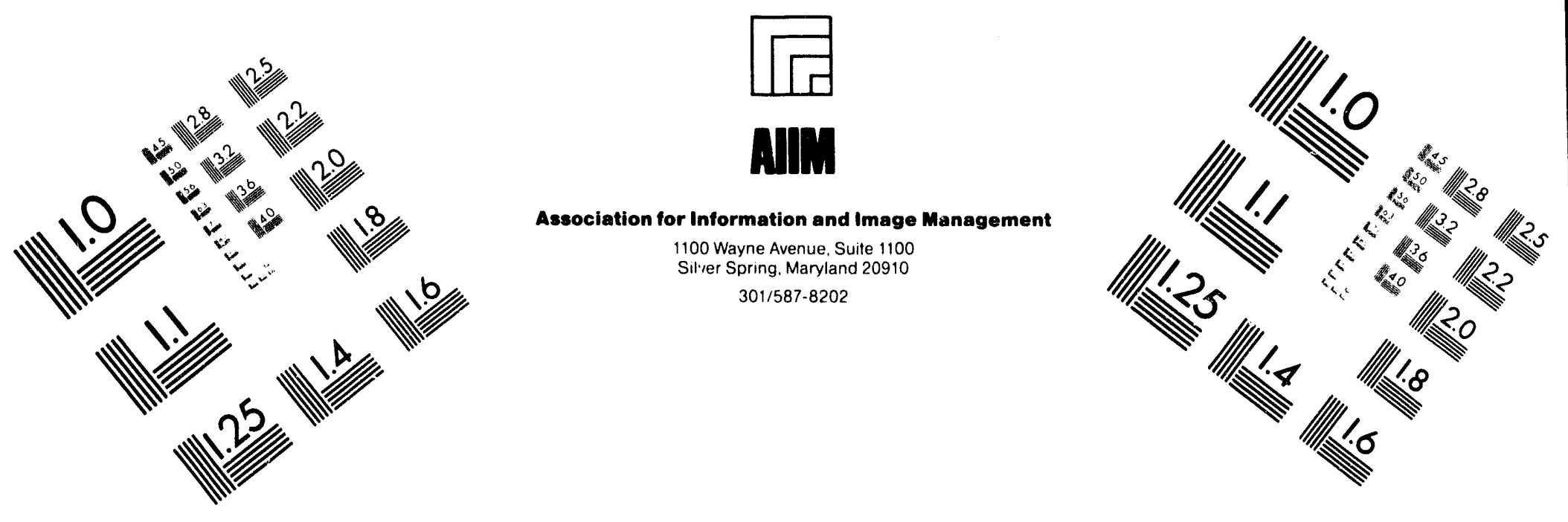

\title{
Centimeter
}

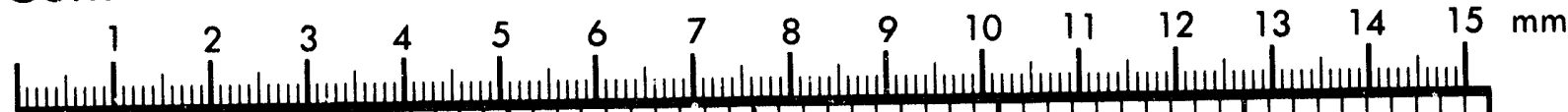

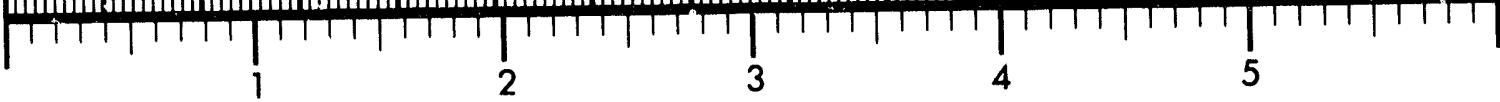
Inches
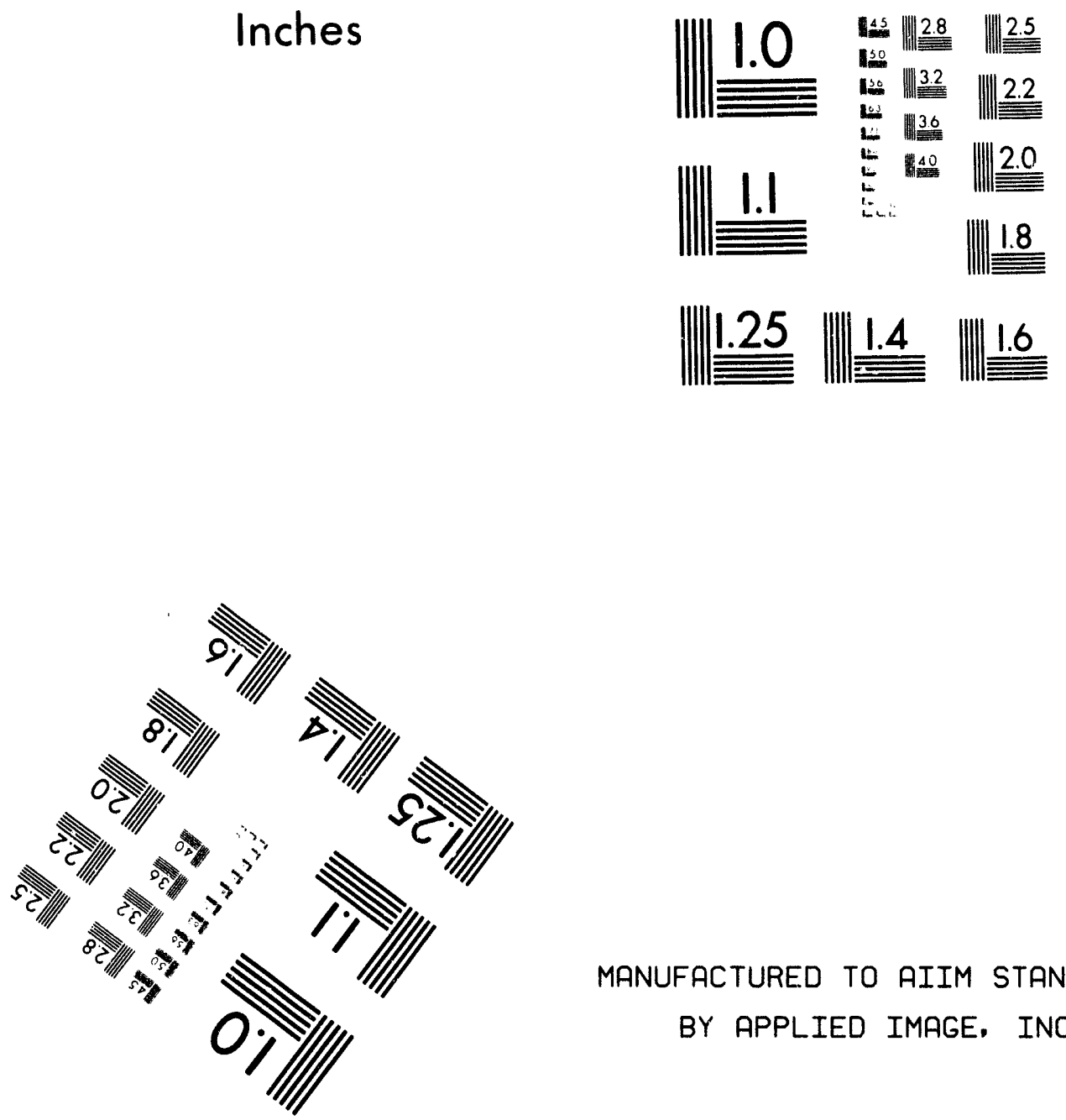

MANUFACTURED TO AIIM STANDARDS

BY APPLIED IMAGE, INC.

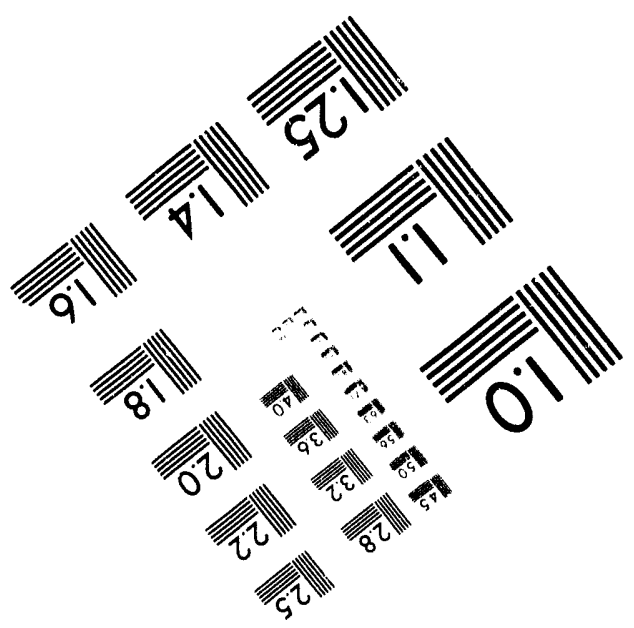



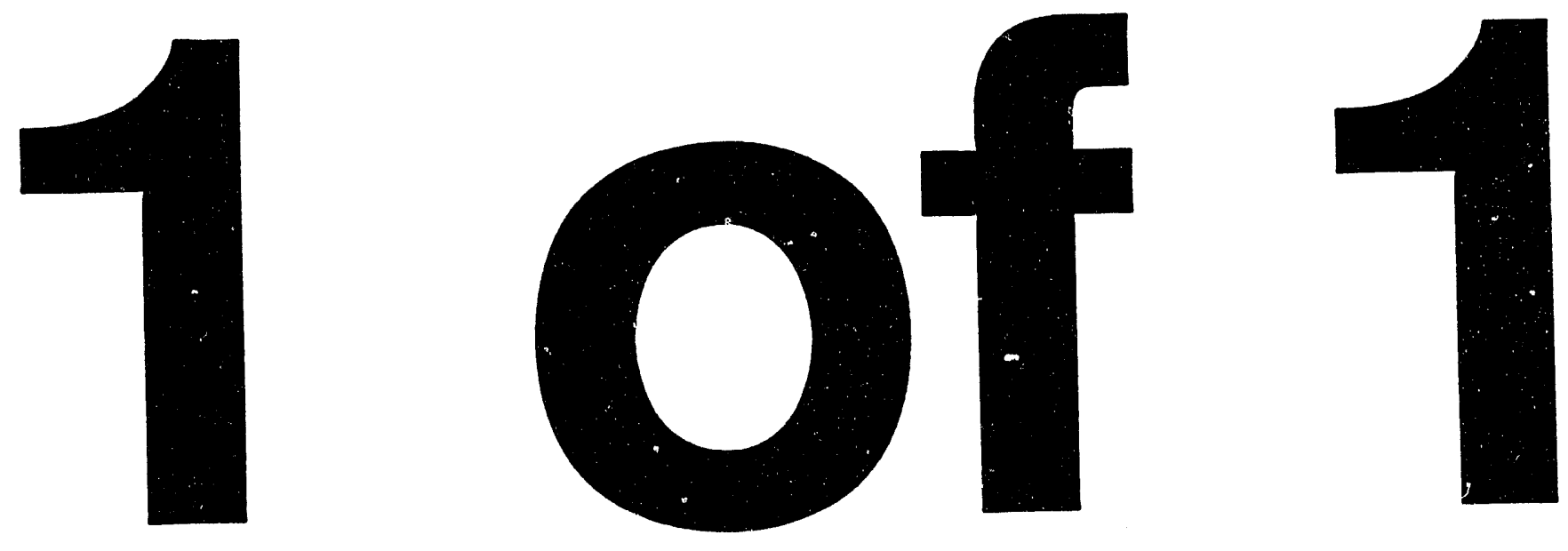
NUREG/CR-6120

\section{Controlled Field Study for Validation of Vadose Zone Transport Models}

Manuscript Completed: January 1994

Date Published: August 1994

Prepared by

P. J. Wierenga/UA, R. G. Hills/NMSU, A. W. Warrick/UA, T. C. Yeh/UA

Contractor

Department of Soil and Water Science

429 Shantz Building \#38

University of Arizona

Tucson, AZ 85721

Subcontractors

Department of Hydrology and Water Resources

Room 122 Harshbarger Building \#11

University of Arizona

Tucson, AZ 85721

Department of Mechanical Engineering

Box 3001, Department 3450

New Mexico State University

Las Cruces, NM 88003-0001

Prepared for

Division of Regulatory Applications

Office of Nuclear Regulatory Research

U.S. Nuclear Regulatory Commission

Washington, DC 20555-0001

NRC FIN L1286 


\begin{abstract}
Prediction of radionuclide migration through soil and groundwater requires models which have been tested under a variety of conditions. Unfortunately, many of the existing models have not been tested in the field, partly because such testing requires accurate and representative data.

of surface area and depth of vadose zone, of an actual disposal area. Experiments are proposed which will yield documented data, of sufficient scale, to allow testing of a variety of models including effective media stochastic models and deterministic models. Details of the methodology and procedures to be used in the experiment are presented.
\end{abstract}

This report provides the design of a large scale field experiment representative, in terms 


\section{TABLE OF CONTENTS}

Executive Summary $\ldots \ldots \ldots \ldots \ldots \ldots \ldots \ldots \ldots \ldots \ldots \ldots \ldots \ldots \ldots \ldots \ldots$

1 Introduction $\ldots \ldots \ldots \ldots \ldots \ldots \ldots \ldots \ldots \ldots \ldots \ldots \ldots \ldots \ldots \ldots \ldots \ldots \ldots \ldots$

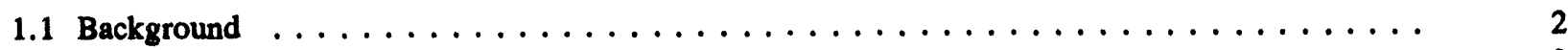

1.1.1 Spatial Variability of Physical Properties $\ldots \ldots \ldots \ldots \ldots \ldots \ldots \ldots \ldots$

1.2 Stochastic Models $\ldots \ldots \ldots \ldots \ldots \ldots \ldots \ldots \ldots \ldots \ldots \ldots \ldots$

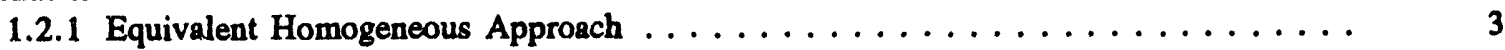

1.2.2 Heterogeneous Approach $\ldots \ldots \ldots \ldots \ldots \ldots \ldots \ldots \ldots \ldots \ldots$

1.3 Validation Methodology $\ldots \ldots \ldots \ldots \ldots \ldots \ldots \ldots \ldots \ldots \ldots \ldots \ldots \ldots \ldots$

1.3.1 Field Scale Experiment for
Unsaturated Soils $\ldots \ldots \ldots \ldots \ldots \ldots \ldots \ldots \ldots \ldots \ldots \ldots \ldots \ldots \ldots \ldots \ldots$

1.3.2 The Design of Model Testing Experiments $\ldots \ldots \ldots \ldots \ldots \ldots \ldots \ldots \ldots$ g

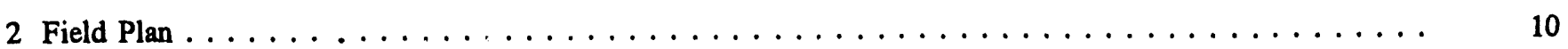

2.1 Experimental Design $\ldots \ldots \ldots \ldots \ldots \ldots \ldots \ldots \ldots \ldots \ldots \ldots \ldots \ldots$

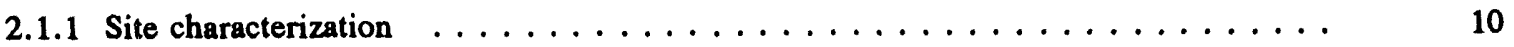

2.1.1.1 Physical properties . . . . . . . . . . . . . . . . . 10

2.1.1.2 Instrumentation $\ldots \ldots \ldots \ldots \ldots \ldots \ldots \ldots \ldots \ldots \ldots \ldots \ldots \ldots$

2.1.2 Preliminary predictions $\ldots \ldots \ldots \ldots \ldots \ldots \ldots \ldots \ldots \ldots \ldots \ldots$

2.1.3 Field measurements $\ldots \ldots \ldots \ldots \ldots \ldots \ldots \ldots \ldots \ldots \ldots \ldots \ldots \ldots$

2.1 .4 Data analysis . . . . . . . . . . . . . . . . . . . . . 14

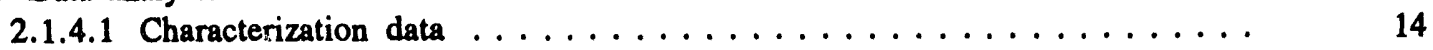

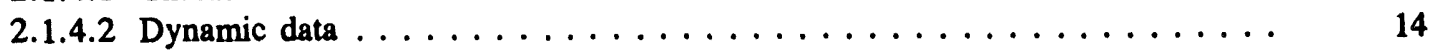

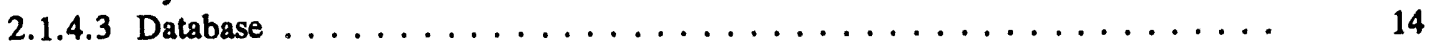

3 Validation of Models and Methodology $\ldots \ldots \ldots \ldots \ldots \ldots \ldots \ldots \ldots \ldots \ldots$

4 References $\ldots \ldots \ldots \ldots \ldots \ldots \ldots \ldots \ldots \ldots \ldots \ldots \ldots \ldots \ldots \ldots \ldots \ldots \ldots \ldots$

Figure

Figure 2-1. Overview of plot with proposed instrumentation locations $\ldots \ldots \ldots \ldots \ldots \ldots$

Table

Table 2-1. Instrument type and depth of measurement at each site 
This technical report was prepared by the University of Arizona under a contract with the Waste Management Branch of the Office of Nuclear Regulatory Research (FIN L1286). This report outlines the design of a large scale field experiment representative, if terms of surface area and depth of the vadose zone, of actual disposal sites.
NUREG/CR-61.20 is not a substitute for NRC regulations, and compliance is not required. The approaches and/or methods described in the NUREG/CR are provided for information only. Publication of this report does not necessarily constitute NRC approval or agreement with the information contained herein. 


\section{EXECUTIVE SUMMARY}

Licensing of low-level radioactive waste disposal sites in the United States requires that sites are capable of being characterized and modelled. Future behavior of these sites needs to be analyzed through performance assessment methodology, which includes modelling of radionuclide migration to groundwater. However, models must be tested before general acceptance of performance assessment can be expected. Such testing requires accurate and representative data. Unfortunately, data sets that can be used for such testing are limited in scope or not available. This is particularly the case for testing stochastic models, which generally require large data sets. The Las Cruces Trench study has provided one such data set which allowed for extensive testing of deterministic, as well as stochastic models. While tests of deterministic models using the Las Cruces data were most successful, those for stochastic models were less successful because the correlation scales of the pertinent hydraulic and transport properties were found to be too large relative to those of the infiltrating plumes to allow for validation of effective media stochastic models.

The purpose of this report is to provide a design of a large scale field experiment representative, in terms of surface area and depth of vadose zone, of actual disposal sites. This design should help evaluate how to adequately characterize large field sites with limited field observations, and how to test characterization methods against a performance assessment methodology. A major benefit of a well designed field experiment is that it provides a documented data set, of sufficient scale, to allow testing of effective media stochastic models, in addition to other stochastic and deterministic models.

A $60 \times 60 \mathrm{~m}$ field plot is proposed, instrumented with neutron access tubes, tensiometers, solution samplers and other equipment appropriate for vadose zone characterization. Measurements are to be taken of the soil hydraulic properties with sufficient detail to allow for quantification of the spatial variability of these properties. A variety of tracers will be applied in a very controlled manner. Repeated measurements will be made of water contents and tracer distributions in three dimensions, down to $30 \mathrm{~m}$ with the data collected made available in a public data base. It will be used to test a variety of models, stochastic and deterministic, for predicting contaminant raigration through deep vadose zone horizons and to test the ability of practical site characterization methodology, to provide sufficient data to adequately predict contaminant plume behavior.

\section{Introduction}

To provide regulatory guidance and to assist in the development of low-level waste disposal facilities, the United States Congress passed the Low Level Radioactive Waste Disposal Act of 1986. As a result, a requirement for the licensing of near surface low-level radioactive waste (LL.W) disposal sites, as set forth in the U.S. Nuclear Regulatory Commission (NRC) regulations (Subpart D of 10 CFR Part 61), is that the site "shall be capable of being characterized, modelled, analyzed, and monitored." One of the major environmental considerations in choosing and engineering a LLW site is the ability to predict and control the transport of LLW materials to the environment through local geological features. LLW materials that leak from their containment areas can reach the groundwater due to deep percolation (recharge), can be taken up by plant roots, and can be released into the atmosphere through evaporation and transpiration.
The various aspects of a LLW site's future behavior, such as releases of radionuclides to groundwater, but also disposal site stability and waste container integrity, are analyzed through performance assessment methodology (PAM). Performance assessment is the formal analysis of a low-level waste disposal site's future behavior in tenns of annual dose to individuals. One critical aspect of performance assessment of a site is the determination of the potential for radionuclide releases via the groundwater pathway. Because the groundwater pathway is considered a primary means for possible exposure, an understanding of the processes which influence transport to groundwater will be critical for acceptance of the license application.

The successful estimation of the concentrations of LLW vaterials that reach groundwater at a particular site are hampered by the complex nature of transport through the vadose zone. While many of the physical processes that control vadose zone transport are well understood 
on the laboratory scale, our ability to model these processes on the field scale has not been established.

Performance assessment relies heavily on the use of models for predicting radionuclide migration. For example, models can be used to show thit worst-case calculations of releases from a proposed disposal site will not exceed the standards set by NRC or another government agency. However, models whether they be conceptual or numerical, require accurate and representative input data. The volume of data needed for models increases dramatically as the models become more complex. Likewise, because physical and hydraulic properties in the unsaturated zone are highly variable, data needs for rodeling transport through unsaturated media become very large. On the other hand, simple models with more limited data needs, could be adequate for providing worst-case predictions or scenarios. Unfortunately, even limited data sets that can be used for worst-case scenario predictions are often not available. Thus there is a great need for field data to test water flow and transport models for the vadose zone. These data must come from wellcharacterized, well-monitored, and well-controlled field experiments.

The Las Cruces Trench Site study is one of the very few studies specifically designed to meet these requirements. It involved measurements and modeling of water and tracer movement in a relatively small, but heavily instrumented field site. Excellent data were obtained, which were used to test a variety of models for predicting water flow and solute transport through unsaturated soils. The testing of deterministic models was more successful than of the stochastic models. This is because the observed solute plumes showed less spreading than expected based on the effective stochastic models (Gelhar, 1984; Mantoglou and Gelhar, 1987) originally used in the design of the experiments. As a result, the correlation scales of the pertinent hydraulic and transport properties relative to the infiltrating plumes were not small enough to allow for validation of effective media stochastic models.

The purpose of this report is to propose the design of a large scale field experiment representative in terms of surface area and depth of vadose zone of actual disposal site conditions. The objective of the large scale field experiment will be to provide data to test a broad range of field scale models, including effective stochastic models. A second objective of the study will be to test field characterization methods which would be applicable to many site characterization efforts. A third objective will be to test the suitability of current site characterization methods against the NRC's Performance Assessment Metl.sdology.

\subsection{Background}

\subsubsection{Spatial Variability of Physical Properties}

The soil physical properties which are used in predictive models vary significantly across a site. These heterogeneities in the soil properties are due to the different soil types or geological formations and due to spatial variability within a single soil type or geological formation. For example, Stockton and Warrick (1971) found a 20 to $30 \%$ variation in unsaturated hydraulic conductivity for a given water pressure across a 40 hectares site consisting of Pima clay loam. Yeh et al. (1985) showed that the unsaturated hydraulic conductivity at a fixed water content can vary by several orders of magnitude for both Maddock sandy loam and Panoche silty clay loam. Unfortunately, the spatial scales of the spatial variability are usually small for unsaturated soils. For example, Jacobson (1990) used directional semivariograms to estimate the correlation length scales for saturated hydraulic conductivity at the Las Cruces Trench Site (Wierenga et al., 1991; Hills et al., 1991). It was found that the scales were less than a meter vertically and several meters horizontally. Complete deterministic characterization of such a site thus requires that core samples be iaken every several meters horizontally, with several core samples taken per meter vertically. Of course, such a detailed site charcterization would be prohibitively expensive both in time and cost and would, in fact, destroy the site.

This uncertainty in site characterization must be accounted for if a model is to be successful at predicting the transport of contaminants. Failure to do so can lead to 1) the underprediction of the masses and concentrations of contaminants that reach the ground water, 2) the underprediction of first arrival times, and 3) an over estimation of the predicted performance of in-situ remediation. The realization of the significance of this uncertainty has led to a re-examination of the techniques used to model water flow and chemical transport. Due to the uncertainty in site characterization, predictive models must not only predict flow and transport in the presence of uncertain spatial variability, but must also provide estimates of the uncertainties of the resulting model predictions. As 
a result of these uncertainties, the failure of more conventional deterministic models to accurately predict contaminant transport to the groundwater and the increased emphasis on prediction in the licensing process, the development of stochastic models has received much attention in recent years. Stochastic models assume that the actual spatial dependence of the transport properties cannot be determined, but the statistical characteristics of the properties can. The models account for the spatial correlation structure of the properties and allow the uncertainties in characterization to be propagated through the model to estimate the corresponding uncertainties in the model predictions.

While many of the physical mechanisms of transport are understood on the laboratory scale, use of models on the field scale has had limited success. Often the validity of a model on a field scale cannot be adequately tested due to the lack of sufficient field data. Even when there are clear discrepancies between field observations and model predictions, it is often not clear whether these discrepancies are due to some inherent inadequacy in the mathematical model or simply due to our inability to adequately characterize the field site. It is clear that before a model (stochastic or deterministic) can confidently be used to predict performance of a site, the model must first be tested (and not simply calibrated) against data on the field scale at a similar site. Unfortunately, the quantity and quality of field data required to test multidimensional models (even on a small field scale) are quite large as is the expense and the time required to obtain this data. In addition, rigorous quantitative model testing procedures for unsaturated flow and transport in spatially variable soils have not been fully established. Simple comparisons of model predictions to observations through some quantitative norm or by qualitative graphical means does not, in itself, constitute model validation. Some form of hypothesis testing should be used. This requires a knowledge of how the statistics of the uncertainties in site characterization and the measurement error affect the statistics of model predictions. Due to the complexities of model testing and the expense of obtaining sufficient data required to give unambiguous results, there have been very few examples of rigorous model testing for unsaturated soils on the field scale.

The increased emphasis on prediction in the licensing process, the uncertain ability of conventional deterministic models to accurately predict contaminant transport to the groundwater, and the recognition of the importance of property uncertainty have led to a reexamination of the techniques used to predict water flow and chemical transport. As a result, it is generally agreed that predictive models must not only predict flow and transport in the presence of uncertain spatial variability, but must also provide estimates of the uncertainties of the resulting model predictions. Because of this need, the development of stochastic models has received much attention in recent years.

\subsection{Stochastic Models}

For stochastic models it is assumed that the spatial distribution of the transport properties at a large-scale field site cannot be determined in detail, but that the statistical characteristics of the spatial variability of the properties can be evaluated, with a reasonable amount of site characterization effort. The statistical characteristics, however, depict the probability of the occurrence of a given spatially varied property field, instead of the specific spatial distribution of the property at the site. Implicitly, it incorporates the uncertainty in the site characterization. Using the statistical information, the stochastic models, then, allow the uncertainties in characterization to be propagated through the models to estimatc the corresponding uncertainties in the model predictions. A detailed review of various stochastic approaches for modeling of groundwater flow and solute transport in aquifers and discussion of their advantages and disadvantages are presented by Yeh (1992). Here, we offer a brief description of the methodologies that have been applied to the investigation of water flow and solute transport in the vadose zone.

\subsubsection{Equivalent Homogeneous Approach}

An important subclass of stochastic models are those that assume that the beterogeneous site approaches an equivalent homogeneous or effective media behavior in the limit as the scale of the contaminant plumes become much larger than the correlation length scales of the hydraulic parameters (i.e. the average size of the heterogeneity). Such assumptions greatly simplify the analysis by allowing the use of the effective parameters with a deterministic model to predict the mean behavior of water flow and solute transport at the site. Models of this kind are called effective stochastic parameter models, and include those developed by Yeh et al., (1985, 1985a, 1985b) and Mantoglou and Gelhar 
NUREG Controlled Field Study

(1987). These models provide recipes for determining the effective transport parameter values that can be used to predict the average transport behavior of contaminants. They can also be used to estimate the variance of the predicted plume (i.e., deviation of the predicted average behavior from the true one).

However, these models have to rely on the assumption that the spatial variability of the soil properties is small so that formulas for the effective parameters and uncertainty estimates can be derived. The assumption of small variability seems justified when the soil is wet, but it is inappropriate for dry soils where large spatial variabilities have been observed in the field (Yeh ct al., 1986). The usefulness of the formulas for predicting the general behavior of contaminant plumes in the very dry vadose zone is, thus, limited. More importantly, effective stochastic models do not provide information about the likelihood or probability of the failure of the model predictions, unless an assumption of the distribution of the model output is made.

\subsubsection{Heterogeneous Approach}

Another class of stochastic approaches is the heterogeneous approach (Yeh, 1992) which includes several techniques such as geostatistics, $A$ unte Carlo simulation, and conditional simulation.

Geostatistics is a method used to estimate or in erpolate the parameter values at locations where no san ples are available. Two important parts of geostatistics are (1) identification of the spatial structure of the variable (i.e., variogram) and (2) interpolation or estimation of the value of a spatially distributed variable from neighboring values, taking into account the spatial structure of the variable (i.e., Kriging or co-Kriging). Thus, the estimation methodology in geostatistics (Kriging) is different from other interpolation or extrapolation techniques. In addition, kriging provides a measure of the probable error associated with estimates of the unknown values. Using geostatistics, one can determine parameter values at any location at a site and obtain a "pseudo-complete" description of the distribution of the properties of the field site. This complete information can, then, be input to a deterministic heterogeneous model for predicting water flow and solute transport. The probable errors associated with the estimates may also be used to evaluate the uncertainty in model prediction. Also, a framework is provided for "scaling up," such as from small cores to field plots (Zhang et al., 1990).
Monte Carlo simulation involves generation of arge number of realizations of possible heterogeneous property fields that conform to the statistical characteristics of the spatial variability of a field site. Each realization of the random property field is in turn input to a deterministic model to simulate water flow and solute transport. Thus, a large number of solute distributions corresponding to the random fields are obtained and they can be analyzed for the expected value, variance, covariance, and distribution of the solute concentration fields. Since a full description of the joint distribution of the properties is required, the results of Monte Carlo simulation can be used to estimate the probability of contaminants from a waste disposal facility reaching the accessible environment.

A more realistic stochastic approach is conditional simulation which is a special kind of Monte Carlo simulation technique. Unlike standard Monte Carlo simulation, it imposes sample values at the sample points. That is, in each realization of the generated random field, parameter values are kept constant and equal to the measured values at observation locations. Therefore, there is no uncertainty in the parameter values at measurement points, other than measurement errors. As a result, many possible realizations of the random property field generated in the previous Monte Carlo simulation which do not agree with data at sample locations are eliminated. Since only a subset of all possible property fields is used, the variance of output from the conditional simulation is smaller than that from the Monte Carlo simulation. The conditional simulation also provides an estimate of the probability of failure of a waste disposal site similar to the unconditioned Monte Carlo simulation. It is believed that conditional simulation is a more realistic approach because it incorporates the data values at sample locations.

Another major advantage of the conditional simulation approach is that it can be used as a tool for evaluating reduction of uncertainty in model prediction due to additional available data. This tool, therefore, allows design of a cost effective site characterization scheme, which also minimizes the degree of uncertainty due to spatial variability of the properties. To meet the need of the licensing and performance assessment of any low-level waste disposal facilities, conditional simulation appears attractive. 


\subsection{Validation Methodology}

Predictive mathematical models are created to quantify the behavior of nature in a convenient form. These models do not necessarily improve the understanding of why certain phenomena occur, but often simply mimic the phenomena. For exarnple, Newton's model, Force $=$ Mass $\times$ Acceleration, does not explain why acceleration is proportional to force (note that mass is nothing more than a proportionality constant to be determined by experiment), it simply mimics observations of force and acceleration. However, since such models prove useful in predicting the actions of nature, they become accepted as valid models of nature.

There is no standard definition as to what a valid model is. Based on the writings of Kuhn (1970), one definition from a scientific perspective is a model that is accepted by a large percentage of the workers in a field. Such acceptance may require tens of years or longer, and models generally accepted as being valid by one generation of scientists may be invalidated by the next. This is because model validity, by this definition, is measured relative to the experiences of the scientific community at the time.

Model validity from a engineering point of view tends to be more problem oriented. Engineering models are generally recognized as approximations and are judged on how well the approximation holds over a range of parameters. Perfect agreement between model prediction and true physical behavior is not required and the quality of the desirea agreement is application specific.

In most fields of engineering, when model validity is questioned, full scale or partial scale prototype experiments can be constructed and performed. In contrast, testing model validity is a much more serious problem for water flow and contaminant transport on the field scale because laboratory experiments do not necessarily scale up. Field experiments on the appropriate scales are usually very expensive and often impractical or even impossible to perform. Errors in predicting contaminant transport can affect the health of the public and the environment for many generations.

Overviews of model validation methodology for hydrology are presented by Gee et al. (1991), Tsang (1991), Neuman (1991), and Ababou et al. (1992). Gee et al. (1991) surveyed the recent vadose zone literature and discussed recent work in model validation, stochastic and deterministic analysis of vadose zone processes, multiphase flow and transport, preferential flow and transport, and several other topics. Tsang (1991) described the modeling processes and suggested that validation should be applied during every step of model development. Tsang's validation methodology is mostly qualitative with the emphasis placed on the consensus of expert groups. Quantitative measures of model validity are suggested by Ababou et al. (1992). They present examples of model validation using several models for solute plume movement and observations of the corresponding plume movement from one of the experiments at the Las Cruces Trench Site (Wierenga et al., 1991; Hills et al., 1991). Ababou et al. (1992) also suggested probabilistic methods to test goodness of fit of a model to field data. However, a disadvantage of using probabilistic methods is that they depend on a good knowledge of the underlying probability distributions of the uncertainties. This requires another model for these distributions which also must be validated thereby adding uncertainty to the validation process.

Validation of performance assessment models are often viewed differently. Regulators generally consider a performance assessment model valid, or at least acceptable, if it is conservative. Thus, the requirement that the model accurately imitates nature is not required. As a result, there is arguable justification to use simplistic models in performance assessment calculations as long as the simplistic models are conservative. However, it is difficult to determine whether a model is conservative if one truly does not understand flow and transport on the large scale. Neuman (1991) argues that to truly understand large scale flow and transport, we should not subordinate "scientific research on geosphere flow and transport to pragmatic needs perceived on the basis of existing performance assessment models." Scientific research should be vigorously supported, expanding "the domain of present knowledge in areas critical to safety assessment." Neuman argues that this is the most likely way to obtain scientific consensus that is lacking at the present time.

Traditionally, model validation in hydrology has sirnply been the comparison of experimental observations to model predictions. Geherally, comparisons between a single model and the experimental data are made graphically and not through quantitative measures. For example, most of the model validation papers presented in the proceedings of the International Conference and Workshop on the Validation of Flow and Transport in 
the Unsaturated Zone (Wierenga and Bachelet, 1988) used qualitative graphical comparisons. Other examples of graphical comparisons for multidimensional unsaturated field experiments are given by Wierenga et al. (1991) and Hills et al. (1991). Quantitative comparisons, such as a root mean square error, aie easy to evaluate, but difficult to interpret since a root mean square error of a particular magnitude may be acceptable for one application but not for another. Simple quantitative measures, such as root mean square error, can be used to rank the performance of several models relative to the data (Warrick et al., 1988). Of course, the model that performs best according to this criterion may not be the best model according to another criterion, such as the maximum observed error. Thus, if quantitative criteria are used, they must be defined relative to the anticipated application of the model.

Quantitative validation strategies for ground water flow and transport have been proposed by several researchers. Davis et al. (1992) have proposed an iterative validation strategy to test both the validity of the model input as well as model structure. They demonstrate the testing of model structure using data from Darcy's original experiment. The model structure is tested by first fitting the model parameters to the experimental data, and then by looking for trends in the residuals. In this example, trends are determined from semi-variograms based on the residuals between prediction and observation. Since they found that a trend did exist in the residuals from Darcy's experiment, they rejected that Darcy's law was validated by his experiment, despite the fact that the error in flux for the worst outlier was only $3 \%$ of the range of fluxes for the experiment. The authors suggest that the invalidation could be due to an inadequate or overly strict validation test, systematic errors in the measurements, or the invalidity of Darcy's law over the range of gradients tested by Darcy. They also investigated the validity of Darcy's law using experimental data from Stearns (1927) at smaller hydraulic gradients and found that this data did not support the rejection of Darcy's law. There are several problems with model validation of this kind. For most engineering applications, an error of only $3 \%$ would be quite good suggesting that their validation test may indeed be too strict for practical applications. Their application of semivariograms tests for the existence of trends relative to the random noise in the data, and penalizes experiments with very little random error. For example, if Darcy had arbitrarily added $10 \%$ random noise to his data, the resulting law may not have been rejected by the methods of Davis et al. (1992).

The existence of spatial variability at a model validation site further complicates the comparisons between model prediction and field data. If spatial variability is to be expected on large scales, and if models must be developed and tested to provide adequate predictions in the presence of such variability, then spatially variable sites must be used for model testing. In this case, significant differences between predictions and observations are to be expected since the characterization of a spatially variable site is uncertain. Due to this uncertainty, it is possible that a model may actually give a higher mean square error than a less valid model for a particular set of observations and input parameters. Thus, one can speak only in terms of the probability that one model is more valid than another for a given set of data or the probability that a model is invalid.

Luis and McL aughlin (1992) propose a methodology whirh is applicable to spatially variable soils. They demonstrate the method by applying it to one of the Las Cruces Trench experiments (Wierenga et al., 1991). Using a stochastic model for water flow based on the ideas of Mantoglou and Gelhar (1987a, b, c), they predict mean behavior for water flow during the Plot 1 experiment. Their stochastic model also provides the mechanism to propagate uncertainty (variances) from site characterization to model prediction. Using the resulting predictions, experimental observations, and estimated uncertainty (variances) in the predictions, uncertainty bounds (at the $95 \%$ confidence level) are placed on the predicted water contints. Luis and McLaughlin then judge model validity by counting the percentage of observed water contents that lie within the uncertainty bounds. This method is intended to test model structure. In contrast to the validation example presented by Davis et al. (1992), the validation example presented by Luis and McLaughlin (1992) utilized model input parameters that were determined from experimental measurements with no re-calibration or parameter fitting to improve agreement between prediction and observation. In addition, the method of Luis and McLaughlin explicitly accounts for site characterization uncertainty. However, as for many other methods that make probabilistic judgements, the method proposed by Luis and McLaughlin requires good knowledge of the underlying probability distributions for the input parameters, and the method implicitly assumes that the propagation of variance analysis, which leads to the error bounds, is $c o$ : $x t$. 
Since the propagation of variance analysis is derived from the stochastic model itself, an invalid stochastic model will lead to false error bounds adding uncertainty to the validation process.

As the previous discussion illustrates, there are considerable problems to be addressed before rigorous model validation or model testing is established. Until such a time, researchers should keep several points in mind.

1. One should assume that any validation technique presently used will likely be iraproved in the future. Thus, all data obtinined from expensive field observations should be well-documented and stored in an easy to access data base. This will allow future researchers to reuse the data for model validation.

2. Validation should be from both a scientific and performance assessment point of view. Performance assessment models are generally required only to be valid in a conservative sense. Much of the complicating physics that exists at a site can be ignored if a simpler but conservative model shows compliance with the regulations. However, models that are conservative for one site are not necessarily conservative for another. Moreover, it is difficult to know when a model is conservative if one does not truly understands the physics and characteristics of a particular site. Thus, scientific development and validation of models should proceed with equal parity. Any validation effort should focus on validation from both perspectives.

3. Developers of stochastic models should keep in mind that if an experiment cannot be practically designed and executed to test a particular stochastic model within the constraining assumptions required by the model, then such a non-testable model is simply an intellectual construct. The developers of stochastic modeis should share the burden with experimentalists in proposing well thought out experiments to test such models.

4. The development and testing of a validation methodology should go hand-in-hand with the development and execution of validation experiments. Otherwise, the proposed validation methodology may not be practical and executable in the field. One should understand that due to our limited experience with quantitative model testing, any validation effort will be as much the testing of the model validation methodology itself as of the predictive models being tested for flow and transport

\subsubsection{Field Scale Experiments for Unsaturated Soils}

While many deterministic and stochastic models have been verified against other models, testing against field data has been limited. For example, the testing of numerical models for the simulation of one-dimensional infiltration in dry soils has been limited largely to comparisons with observation of water movement in laboratory columns. To our knowledge, there have been relatively few well-defined, well-controlled field scale experiments for water flow and solute transport in unsaturated soils. McCord et al. (1988) monitorec' unsaturated flow and transport in a small sand dune located in the Sevilleta National Wildlife Refuge $25 \mathrm{~km}$ north of Socorro, New Mexico. Dry bromide salt was buried at select locations to create tracer plumes under natural rainfall conditions. Solute concentrations were evaluated using soil samples taken with a $1.5 \mathrm{~cm}$ soil sampler. Comparisons between model predictions and experimental observations were made. However, since the upper boundary conditions were not well-defined, the experiment was not well-suited for rigorous quantitative model testing. In a second experiment performed near Socorro, Stephens et al. (1988) applied water with tracers through a drip irrigation system to a 10.5 by $10.5 \mathrm{~m}$ square area situated over a stratified formation consisting of fluvial sand and alluvial silty sand deposits. Water flow was monitored with tensiometers and neutron probes over a 30 by $30 \mathrm{~m}$ area surrounding the irrigation system. Solute samples were taken through solution samplers during the experiment and from soil samples taken after the experiment.

Unfortunately, there were problems with the water flow measurements and evidence of locally saturated conditions including saturated flow along the sides of the tensiometers and solute samplers. As a result, the data from the experiments are questionable and the data have not been used for rigorous model testing.

In recent experiments by Ellsworth et al. (1991) and Ellsworth and Jury (1991) in an agriculture research field at Etiwanda, California, solute plumes in unsaturated soils were created using two methods. In the first, a solute application system consisting of drip emitters under a water shedding frame was used to apply solute over ten 2.25 to $4.0 \mathrm{~m}^{2}$ areas. The application systems were run concurrently with a field wide sprinkler system. Water from the field system 
falling on a water shedding frame was diverted through a gutter to a location $8 \mathrm{~m}$ away. After solute application was complete, the application system was displaced laterally $8 \mathrm{~m}$. Application of water through the field sprinkler system was continued moving the plume deeper into the soil formation. In the second solute application method, solute was mixed with soil removed from the top $5 \mathrm{~cm}$ of two application areas using a concrete mixer. The resulting soil mixture was returned to the corresponding application areas and packed in place using three lifts. Core samples we.e takeu using a $6.35 \mathrm{~cm}$ diameter split sampling tube encased in a $18 \mathrm{~cm}$ diameter auger. The samples were analyzed for water content and solute concentration. The observed solute plumes were characterized using moment analysis. Transfurmed vertical velocities and dispersion coefficients were estimated using a onedimensional model for transport. Ellsworth et al. (1991) found that both the bulk density and the solute transport behaved in a remarkable homogeneous fashion laterally (soils are thought to be part of an alluvial fan) but significant spatial variability existed in the vertical direction. Other work performed at the Etiwanda, California field site is surveyed by Gee et al. (1991). This work includes using field data to compare onedimensional, deterministic, convective-dispersive models to stochastic convective transfer function models (Butters and Jury, 1989 and Russo et al., 1989a,b).

The unsaturated field scale experiments that, to our knowledge, have received the most attention from multi-dimensional numerical modelers are the Las Cruces Trench Experiments (Wierenga et al., 1989, 1990, 1991; Hills et al., 1991). These experiments were specifically designed to test models for water flow and solute transport. The experiments are located at a test facility on the New Mexico State University College Ranch. A trench, $25 \mathrm{~m}$ long, $5 \mathrm{~m}$ wide and $6.5 \mathrm{~m}$ deep, was excavated in undisturbed soil. The walls of the trench were excavated vertically and the trench was covered to divert the rainfall away from the trench area. Liner material was added adjacent to the trench to minimize natural infiltration. During the construction of this trench approximately 600 core samples and 600 disturbed soil samples were taken in a vertical plane along the north trench wall to determine the soil-water properties of the soil. These data were acquired in sufficient quantity so that stochastic models for spatial variability of soil properties for the site could be generated. The soil water retention curve in the wet range, the saturated hydraulic conductivity, and the bulk density were determined for each core sample through conventional laboratory tests. Water retention data in the dry range and particle size distributions were determined for each disturbed sample. In addition to the laboratory tests, saturated hydraulic conductivity values were estimated in-situ by the Guelph permeameter (Reynolds et al., 1985). The soil water retention data generated from the laboratory tests were used to estimate water retention parameters for van Genuchten's model (1978). Contour plots of the resulting parameters indicate that the soil is highly spatially variable over the $6 \mathrm{~m}$ deep by $25 \mathrm{~m}$ wide sampling grid (Wierenga et al., 1990, 1991).

In a series of three dynamic experiments performed at the site, water with various tracers was applied through carefully controlled drip irrigation systems to two sites adjacent to the trench. The irrigation areas and large areas surrounding them were covered with pond liner to inhibit evaporation and to eliminate infiltration due to rain and surface runoff. The movement of water and tracers through the soil profile were mowitorol with an array of tensiometers and solute samplers insterted through the trench wall, and with a neutron rrobe inserted in access tubes located along six, twodimensional vertical planes at the site. Of the three experiments, the third utilized the most exhaustive sampling grid with solute concentrations, tensions, and water contents monitored at approximately 100,100, and 1000 locations respectively as a function of time.

The Las Cruces trench experiments are part of the INTRAVAL international model validation effort. INTRAVAL is a consortium of 22 organizations from 12 countries organized by the Swedish Nuclear Power Inspectorate to develop validation methodologies and to test geosphere models for the transport of radionuclides. To provide easy access to the data, a relational database was assembled using the characterization and dynamic experimental data. It is accessible through the national computer networks. Scientists, from Massachusetts Institute of Technology, Pacific Northwest Laboratory. Sandia National Laboratories, the Center for Nuclear Waste Regulatory Analysis, HydroGeologic Inc., Kemakta, and New Mexico State University have used or are using the data to compare the model predictions of unsaturated water flow and solute transport to field observations. The models range from simple, uniform soil, deterministic, one-dimensional models to fully heterogeneous, three-dimensional stochastic models. The comparisons between the results of the first two experiments and the corresponding model predictions for water fiow and solute transport are documented in Voss (1992), Wierenga et al. (1991), and Hills et al. (1991). Comparisons between model predictions and 
field observations for the third experiment are currently underway. The third experiment is unique in that the modelers do not have access to field data when making their predictions. These predictions are supplied to New Mexico State University (NMSU) for analysis. NMSU compares predicted and experimental point values, first detection times at specific horizons, integrated values such as zeroth, first, and second moments of the resulting plumes, and fluxes through specific horizons for the water and solute plumes. These comparisons are made qualitatively through graphs and quantitatively using statistical procedures.

The Las Cruces experiments, designed to test deterministic and stochastic models for water flow and solute transport, have proven quite successful in testing deterministic models, but less so in testing stochastic models. Based on the information available at the time, the effective media stochastic models used to design the experiment predicted that the infiltration plumes would possess horizontal length scales that were large (approximately $10 \mathrm{~m}$ ) compared to the length scales of the spatial variability (approximately $2 \mathrm{~m}$ ), even though the water was applied over a relative narrow strip of drip irrigators ( 1 to $4 \mathrm{~m}$ wide). When the experiments were performed, the actual plume spreading was significantly less than anticipsted. Thus, the effective media stochastic models that required length scales of the infiltrating plumes to be large compared to the length scales of the spatial variability could not be adequately tested. In designing a new experiment, the drip application systems for the experiment should cover a large area relative to the correlation scales. The resulting plumes would thus already be of sufficient horizontal scale without the need for additional plume spreading.

Stochastic models provide the best hope in predicting water flow and contaminant transport on the large scale. However, if such models are to be trusted in predicting performance of waste isolation sites or insitu remediation technologies, then they must be tested against field data on the appropriate scale. There is a great need to develop field scale experiments and to develop the corresponding quantitative model testing methodologies.

\subsubsection{The Design of Model Testing Experiments}

The design and execution of field experiments to test stochastic and deterministic models for water flow and solute transport in unsaturated soils require close interaction between the experimentalist and the modelers. For such an experiment to be successful, the following should be considered:

1. The type of model to be tested greatly affects the experimental design. The experimental designer must work closely with the modelers to identify the statistical characteristics of soil properties that must be present before the model can be adequately tested.

2. The site characterization methodology must be developed in close cooperation with the modelers so that the required statistical characterization of the site can be determined with sufficient resolution.

3. Continued communication between the modelers and the experimentalist must take place during site characterization so that the characterization procedures can be modified as data are analyzed.

4. Once the site is characterized, the results should be reviewed to insure that the site does indeed meet the criteria set in item 1.

5. After site characterization, the experiments should be modeled prior to their execution to help optimize the locations of the sensors, the water and solute application rates, the sampling rates, and the duration.

6. At this point, the experiment can be constructed and executed. During execution, the dynamic variables being monitored (water contents, tensions, solute concentrations) should be analyzed in a timely fashion so that modifications can be made while the experiment is underway. All data should be stored in an easily accessible database. Based on the design criteria listed above, sufficient information will be available to test a variety of stochastic and deterministic models. The data can also be used for sensitivity analyses with models which use only subsets of the data collected. These analyses should make it possible to help establish minimum data sets required to adequately characterize low level nuclear waste disposal sites. Performance assessment methodology may also be applied to predict exposure of man and environment to contaminants and radionuclides 


\section{FIELD PLAN}

The purpose is to develop a large, controlled field experiment to observe unsaturated contaminant transport at the field scale; similar to the Las Cruces Trench experiments. However, the experiment proposed here should be larger (e.g. larger surface area, and deeper) and does not have to involve the construction of a trench. Objectives of the study are to develop data on contaminant transport and site characterization for model validation, and to test the adequacy of practical field site characterization methods.

The study should be conducted on land belonging to a State or Federal Agency, and under control of that agency.

\subsection{Experimental Design}

The field program will have four components. These are

1. Site characterization

2. Preliminary predictions

3. Field measurements

4. Data analysis

The project needs to be conducted on a field site which is at least 5 acres in size. The site should be enclosed within a larger property of no less than 500 acres under control of a State or Federal agency. This ensures that access is guaranteed for the duration of the experiment and possibly for much longer. A 0.4 acre field plot should be established in the center of the field site (Fig. 2-1). This plot should be heavily instrumented with neutron probe access tubes, tensiometers and solution samplers. Before, during and after application of water containing a variety of tracers, repeated measurements should be taken of the water content and tracer distributions in three dimensions. The data obtained on water and tracer distributions need to be stored in a digital data base and made available for general use. The data can be used by the P.I.'s of this project, and other interested scientists and engineers to test a variety of models for predicting solute transport through deep vadose zone horizons.

\subsubsection{Site characterization}

\subsubsection{Physical properties}

The physical and chemical properties of the soil at the site need to be known for the model testing. At a minimum, the hydraulic conductivity $(\mathrm{K}(\theta))$ and pressure potential (h) need to be known as a function of water content $(\theta)$. In addition to the magnitudes, their variabilities are needed. Variability is characterized not only by the overall variance and distribution, but also the correlation lengths and the degree of interdependence. In order to determine the correlation lengths, some attention needs to be given to the spatial distribution of samples. The determination of how many samples are needed is one of the objectives of this study.

Site characterization will be initiated by taking undisturbed core samples down to $30 \mathrm{~m}$ at 4 locations immediately around the plot area. The cores will be collected at $0.5 \mathrm{~m}$ intervals on three of the locations and at $0.25 \mathrm{~m}$ intervals on the fourth. The cores will be taken to the laboratory for determination of the $\mathrm{K}(\theta)$ and $h(\theta)$ relationships. We suggest that methods based on the one-step outflow procedure (Kool et al., 1985), but improved by the soil physics group at The University of Arizona in Tucson (Hudson et al., 1991) be used for these analyses. With adequate instrumentation (pressure cells, transducers, balances and dataloggers), a large number of core samples can be run automatically within a reasonable time frame. The core samples should also be used for bulk density determinations and saturated hydraulic conductivity measurements.

The spatial correlations in the vertical distance can be determined using the $0.25 \mathrm{~m}$ increment core samples of the fourth location. The other three borings will be useful for the larger increments. The horizontal correlation lengths will be based on samples at an additional 100 locations at the $0.25 \mathrm{~m}$ depth. Fifty of the additional horizontal sampling locations will be on a grid encompassing the study area; the final fifty will be arranged so as to give an "optimum" distribution of separation couples (Warrick and Myers, 1987). This will result in 104 values on which to compute sample variograms in a horizontal plane at $0.25 \mathrm{~m}$. This can be combined with information of 120 depths in the 
detailed vertical transect and the additional 180 values from the remaining 3 vertical borings.

A restricted number of cores (approximately 10) should be used to determine preliminary solute dispersion coefficients for the various horizons, using the methodology of van Genuchten and Wierenga (1986).

The hydraulic properties of the soil at the site may also be determined in situ from soil water redistribution data (Hillel, 1980). The internal drainage method is generally considered the standard method for field determination of the unsaturated conductivity. It involves detailed measurements of water content $(\theta)$ and tension (h) with depth and time, while preventing surface evaporation. The method can be applied at the end of an irrigation cycle, when water input at the upper surface of the field plot is terminated.

The initial water content and tracer concentrations in the plot can be determined during installation of the neutron probes, tensiometers and solution samplers.

\subsubsection{Instrumentation}

Instrumentation should be installed on two perpendicular diagonals through the $60 \mathrm{~m} \times 60 \mathrm{~m}$ experimental plot (Fig. 2-1). The type of instrumentation and suggested depths of installation at each measurement site are shown in Table 2-1. In order to reduce the number of measurements, readings or samples will be taken at five depths only. However, there are 29 instrument locations, and sampling at only 5 depths results in a total of 145 measurements for each round of sampling. Although this is a large number of measurements, such detailed information is necessary for a full characterization of the three dimensional tracer plume in the unsaturated zone below the plot area. All instruments should be installed vertically down from the soil surface. The three instruments at each site will be separated by a horizontal distance of 0.5 meter to minimize the effects of one instrument on the other. Two inch steel tubes should be used as access tubes for the neutron probes. They are to be driven down through 2-inch ID holes drilled to the desired depth to ensure good contact between the tubes and the surrounding soil. Soil samples should be taken during tube installation for neutron probe calibration.

Tensiometers are to be installed through one-inch or two-inch ID access holes to a maximum depth of 10 meters. Measurements below 4 meters should be made with pressure transducers mounted near the porous cup.

Both ceramic and stainless steel suction probes may be used for collecting soil solution samples. The porous stainless steel probes are preferred for the deeper depths because of their greater strength and inertness with respect to organic tracers. All solution samples will be collected in glass containers and sent to a laboratory for analysis.

\subsubsection{Preliminary predictions}

Once sufficient characterization data are availuble, numerical modeling is to be used to further refine the experimental design. A deterministic numerical finite difference or finite element model for water flow and solute transport should be used to approximate the response of the experimental system under various water and tracer application rates and durations. The results of the numerical modeling will help define water and tracer application histories so that the travel distances of the corresponding plumes are large compared to the correlation scales of the spatial variability of the soil properties during the duration of the experiment. In addition, the numerical results will help refine initial placement of the tensiometers, solute samplers, and neutron probe access tubes. Since the deterministic models may predict different plume geometries than will be present in a spatially variable

Table 2.1 Instrument type and depth of measurement at each site.

\begin{tabular}{|c|c|c|c|}
\hline Depth $(\mathrm{m})$ & Neutron-probe & Tensiometer & Solution Sampler \\
\hline 1 & $\mathrm{X}$ & $\mathrm{X}$ & $\mathrm{X}$ \\
2 & $\mathrm{X}$ & $\mathrm{X}$ & $\mathrm{X}$ \\
4 & $\mathrm{X}$ & $\mathrm{X}$ & $\mathrm{X}$ \\
10 & $\mathrm{X}$ & $\mathrm{X}$ & $\mathrm{X}$ \\
30 & $\mathrm{X}$ & - & - \\
\hline
\end{tabular}




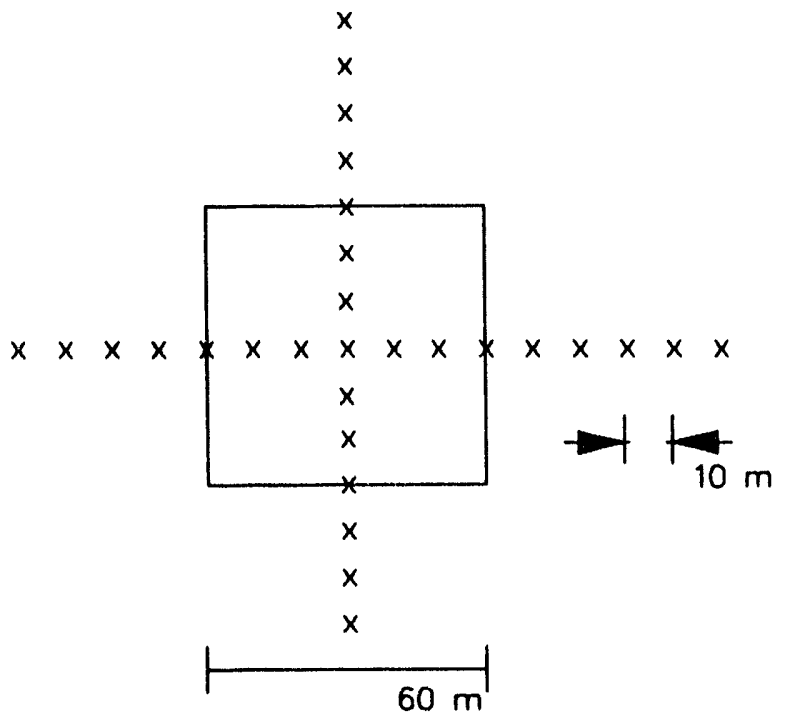

Figure 2-1. Overview of plot with proposed instrumentation locations.

soil, the numerical results will be used only as guidelines on the initial instrumentation placement. Additional field instrumentation should be installed as needed based on actual observations of water movement during the experiment.

For the preliminary analysis, the irrigated area can be assumed to be in the form of a circular disk of area $3600 \mathrm{~m}$ rather than in the form of a square as shown in Figure 2-1. This approximation allows cylindrical symmetry to be assumed resulting in much simpler two-dimensional (radius and depth) numerical simulations. This approximation improves as the plume moves away from the irrigated area.

Richards' equation for two-dimensional water flow in cylindrical coordinates with isotropic hydraulic conductivity is given by:

$$
\frac{\partial \theta}{\partial t}=\frac{1}{r} \frac{\partial}{\partial r}\left(r K \frac{\partial h}{\partial r}\right)+\frac{\partial}{\partial z}\left(K \frac{\partial h}{\partial z}-K\right)
$$

where $\theta$ is the volumetric water content, $\mathrm{K}$ is the hydraulic conductivity, $h$ is the matric potential, $t$ is time, $r$ is the radial position, and $z$ is the vertical position measured downward.
The initial and boundary conditions on water content are taken to be

$$
\begin{gathered}
h(r, z, 0)=h_{\text {hat }}(z) \\
\left.\left(K-K \frac{\partial h}{\partial z}\right)\right|_{z=0}=q_{\text {mato }}(r, t) \\
\left.\left(K-K \frac{\partial h}{\partial z}\right)\right|_{z=b}=0.0 \\
\left.\frac{\partial \mathbf{h}}{\partial z}\right|_{z=0}=0.0
\end{gathered}
$$

where $a$ and $b$ are sufficiently large, and the initial water contents sufficiently small so that significant water movement does not occur near to these boundaries during the simulation. Values of $a$ and $b$ will be determined through numerical experimentation. The initial conditions, the parameters in the water retention relationships, and the parameters in the unsaturated hydraulic conductivity models will be measured or estimated during the site characterization process.

To model the transport of the tracers during this stage, the convection/dispersion equation will $t e$ used with the assumption that the dispersivity is homogeneous and isotropic and that the solute is nonreactive and non decaying. The governing partial differential equation is given by

$$
\begin{aligned}
\frac{\partial}{\partial t}(R \theta c) & =\frac{1}{r} \frac{\partial}{\partial r}\left(\mathrm{rD}_{\mathrm{s}} \frac{\partial c}{\partial z}-\mathrm{rq}_{\mathrm{r}} \mathrm{c}\right) \\
& +\frac{\partial}{\partial z}\left(\theta \mathrm{D}_{\mathrm{s}} \frac{\partial c}{\partial z}-\mathrm{q}_{z} \mathrm{c}\right)
\end{aligned}
$$

where $R$ is the retardation factor, $D_{1}$ is the dispersion coefficient, $q_{r}$ and $q_{2}$ are the Darcian fluxes, and $r$ and $z$ are coordinate directions. A normalized or relative concentration can be used for $c$ where the normalization constant is the average concentration applied during the solute pulses. Thus normalized concentration for the solute applied at the surface is unity. The $r$ and $z$ components of the Darcian fluxes are given by

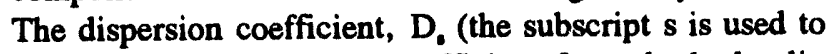
distinguish the dispersion coefficient from the hydraulic 


$$
\begin{aligned}
q_{r} & =-K \frac{\partial_{h}}{\partial x} \\
q_{z} & =K-K \frac{\partial \mathbf{h}}{\partial z}
\end{aligned}
$$

diffusivity, D), is given by

$$
\theta D_{s}=\theta D_{m}+\epsilon|q|
$$

where $D_{m}$ is the molecular dispersion coefficiert, $\epsilon$ is the dispersivity, and $|q|$ is the magnitude of the Darcian flux. Here the dispersivity and molecular dispersion coefficient can be assumed to be homogeneous and isotropic leading to a dispersion coefficient that is a scalar. Dispersivity values measured during site characterization will be used.

The initial and boundary conditions for the relative concentration $c(x, z, t)$ will be

$$
\begin{gathered}
c(r, z, 0)=c_{\operatorname{lnh}}(r, z) \\
\left.\left.\left(q_{z} c-\theta D, \frac{\partial c}{\partial z}\right)\right|_{z=0}=q_{\text {solute }}(r, t)\right) \\
\left.\left(q_{x} c-\theta D_{3} \frac{\partial c}{\partial z}\right)\right|_{z=b}=0.0, \\
\left.\left(q_{r} c-\theta D_{s} \frac{\partial c}{\partial r}\right)\right|_{r=0}=0.0,
\end{gathered}
$$

Again, the $a$ and $b$ will be taken sufficiently large so that the wetting and solute fronts do not interact with the boundaries during the numerical simulation. Efficient algorithms, such as the finite difference algorithms of Hills et al. (1991) and Kirkland et al. (1992) should be used to solve Richards' equation. These algorithms have proven to be very CPU efficient and will only require minor modification for cylindrical coordinates. If the dispersion coefficients are found to be large, conventional convective/dis-persive algorithms, such as the one presented in Hills et al.
(1991) can be used to model tracer transport. If the dispersion coefficients are found to be small, high Peclet number algorithms, such as the Flux Corrected Transport (FCT) algorithm should be used. Numerical experiments with the FCT algorithm (performed at New Mexico State University) as applied to convective/dispersive transport in heterogeneous soils have shown the algorithm to be suitable for both convective/dispersive systems and for strictly convective systems. Quality control of the numerical simulations will include checks with appropriate 1-dimensional simulations and analytical solutions.

\subsubsection{Field measurements}

The purpose of this study is to test flow and transport models at the field scale. For this purpose, exact knowledge of the boundary conditions, in particular the flux in or out of the plot surface, is necessary.

Water should be applied to the plot with a drip irrigation system, consisting of parallel driplines, spaced $0.3 \mathrm{~m}$ apart with emitters on a $0.3 \mathrm{~m}$ spacing along each dripline. To apply water through a drip system with emitters on a $0.3 \mathrm{~m} \times 0.3 \mathrm{~m}$ grid over the $3600 \mathrm{~m}^{2}$ area of the plot, requires a total of 40000 emitters. The application area may be revised if the site characterization and initial modeling results suggest a change. Evaporation from the plot surface may be prevented by placing heavy duty plastic over the soil surface, over the drip lines. Pond liner was found to be most suitable at the Las Cruces Trench Site (Wierenga et al., 1990).

The amount of water applied should be measured volumetrically, and also by using two well calibrated water meters, placed in series.

Tracers should be applied with the water at two time intervals. The first tracers should be applied when the water is initialiy added to the plot. The second group of tracers should be applied when the water front has reached the lower depth of the soil profile (e.g. $30 \mathrm{~m}$ ). At that time, the water content in the soil near the system will have reached a near constant value, and flow should be steady state.

The rate at which the water is applied will depend on the physical properties of the surface soil. Preferably, a rate between 5 and $25 \mathrm{~cm} /$ day (surface flux) should be used. 


\section{NUREG Controlled Field Study}

The main tracers to be used in the experiment are bromide, chloride, nitrate and a number of fluorobenzoic acids. Where possible, tritium should be used. Tritium is essuntially a non-interacting tracer and considered by many as the ideal tracer for contaminant transport studies. Other tracers could be added if necessary.

\subsubsection{Data analysis}

To help insure the successful acquisition, storage, analysis, and distribution of the data, procedures such as those developed by Wierenga, et al. $(1989,1990)$ should be used. Two types of data will be collected. These are site characterization data developed from in-situ and laboratory experiments, and dynamic data acquired during the irrigation and redistribution phases of the field experiment.

\subsubsection{Characterization data}

The characterization data set includes water retention data, measurements of unsaturated hydraulic conductivity as a function of water content (or tension), and solute dispersion data for the various soil horizons. The methods used to acquire these data were discussed before. Standard non-linear estimation procedures will be required (see Wierenga et al. (1989)) with the water retention and unsaturated conductivity data to estimate the parameters that appear in the corresponding soil-water hydraulic property models. In addition, the numerical algorithms similar to those developed by Hudson et al. (1991) should be used to evaluate the uniqueness and accuracy of the parameter estimates for several of the core samples.

The hydraulic parameters for the soil at the site should also be estimated using field observations of the water redistribution. This will be done using the one-dimensional internal drainage method discussed by Hillel (1980) and using a two-dimensional transient parameter estimation procedure based on Richards' equation for a cylindrically symmetric system (specifically, Eqs. (1) and (2)). The second method will yield estimates of the effective soil-water hydraulic properties over the scale of the experiment.

Estimations of correlation scales may be performed based on the detailed areally-distributed data collected for the $0.25 \mathrm{~m}$ depth (104 locations) and vertical distribution based on the 4 borings. Variogram models can be developed based on both weighted-least squares and on negative log likelihood functions (Samper and Neuman, 1989; Warrick et al., 1990). The horizontal distributions can be explored both on global and directional bases; the vertical distributions should be run independently and then combined with the horizontal values. Scaling effects and stationarity are difficult to determine. The techniques of Russo and Jury (1987) may be utilized, including application of fractal dimensional analysis, in order to discern whether drift is present.

\subsubsection{Dynamic data}

The dynamic data include solute concentrations, tensiometer readings, and neutron probe readings for water content. The chemical analysis of the solution samples is very labor intensive and the processed data frowi the solution analyses will have to be hand entered into the database. As a result, there is expected to be a time lag between the acquisition of the solute samples and the determination of solute concentrations.

In contrast, tensiometer and neutron probe readings can be stored electronically and can be processed and made available in digital form to the participating researchers rapidly. This is advantageous because these data allow the water plume to be monitored as it moves through the soil profile, which in-turn helps define where additional instrumentation must be installed as the experiment proceeds. The digitally acquired tensiometer and neutron probe data should be computer graphed to check for consistency, processed into data base format, and uploaded directly from the field to a computer database.

\subsubsection{Database}

The site characterization and dynamic data should be stored in a computer database similar in form to that used for the Las Cruces Trench Experiments (Wierenga et al., 1989, 1990, 1991). Redundant copies of the data will be stored at a second location. The data should be accessible to participating researchers through Internet using FTP. 


\section{Validation of Models and Methodology}

While there is no clear consensus as to what the phrase "model validation" means, there is agreement that the best and perhaps the only way to build confidence in predictive models and the associated site characterization techniques is to test these models against carefully designed and controlled field scale experiments. How one actually compares predictions to observations is not obvious. Traditionally, these comparisons have been made through graphical means which tended to ignore the importance of uncertainty of site characterization in model testing which can lead to ambiguous results. As more field data and more models become available, the quantification of the uncertainties of these comparisons becomes more important. Unfortunately, such statistical comparisons require knowledge of the underlying probability structures of the quantities being compared. Due to the strong spatial and temporal correlations of predictive errors and the nonlinear relationship between parameters used to characterize a site and the model predictions, models for the underlying probability structures have been difficult to establish. Quantitative model testing methodology based on statistical measures must be developed if we are to reduce the ambiguous nature of present model testing techniques. The development of such methodology is worthwhile because it forces us to look explicitly at the nature of the uncertainties associated with model predictions and because such methodology will maximize the scientific return gained from the use of expensive-to-obtain field data. The development of such methodology must occur in parallel with the development of validation experiments since field data and model predictions are required to test the validation methodology and since validation methodology is required to test model predictions using field data.
The original intent of the Las Cruces Trench Experiments was to provide data to test effective media stochastic models of water flow and solute transport. Effective media stochastic models (Mantoglou and Gelhar, 1985, 1987a, 1987b, 1987c) appear to be a practical alternative for spatially variable systems if the models prove to be valid for the field conditions at a site. The models are sufficiently developed, fairly straight forward to apply, and do not require excessive computer resources. Unfortunately, the behavior of the water and solute plumes as predicted by the earlier stochastic models used to design the Las Cruces experiments was different than the behavior observed during the experiments (much less lateral plume spre-ding than predicted). The lateral dimensions of the plume during infiltration and the early stages of redistribution were not sufficient for the assumptions of the stochastic models being tested to be valid. As a result, most of the model testing completed to date has been the side by side comparisons of observed and predicted contour plots of water content and solute concentrations for deterministic models or for single realizations of Monte-Carlo models. These efforts are presently being documented by INTRAVAL, an international geosphere model validation consortium.

The experiment proposed here will be the first to provide data on sufficient spatial scales to test effective media stochastic models for water flow and contaminant transport in the vadose zone. In addition, the data generated will allow the model validation procedures themselves to be demonstrated and tested using a field scale data set. Finally, testing the ability of models to predict field observations using site characterization data will provide insight into the efficiency of current site characterization methodology and the strategies used to support performance assessment.

\section{References}

Ababou, R., B. Sagar, and G. Wittmeyer. 1992. "Testing Procedures for Spatially Distributed Flow l.odels," Advances in Water Resources, 15:181-198.

Butters, G.L, and W.A. Jury. 1989. "Field Scale Transport of Bromide in an Unsaturated Soil, 2. Dispersion Modeling," Water Resourc. Res., Vol 25.
Davis, P.A., N.E. Olague, and M.T. Goodrich. 1992.

"Application of a Validation Strategy to Darcy's

Experiment," Water Resources, 15:175-180.

Davis, P.A., N.E. Olague and M.T. Goodrich. 1991. NUREG/CR-5537, "Approaches for the Validation of Models Used for Performance Assessment of High-Level Nuclear Waste Respositories," U.S. Nuclear Regulatory Commission. 
Ellsworth, T.R., W.A. Jury, F.F. Ernst, and P.J. Shouse. 1991. "A Three-Dimensional Field Study of Solute Transport Through Unsaturated, Layered, Porous Media: 1. Methodology, Mass Recovery, and Mean Transport," Water Resourc. Res., Vol. 27, No. 5.

Ellsworth, T.R., and W.A. Jury. 1991. "A ThreeDimensional Field Study of Solute Transport Through Unsaturated, Layered, Porous Media: 2.

Characterization of Vertical Dispersion, "Water Resourc. Res., Vol. 27, No. 5.

Gee, G.W., C.T. Kincaid, R.J. Lemilard, and C.S.

Simmons. 1991. "Recent Studies of Flow and

Transport in the Vadose Zone, " Rev. of Geophys., Supplement p. 227-239, U.S. National Report to Intern. Union of Geodesy and Geophysics, 1987-1990.

Gelhar, L.W. 1984. "Stochastic Analysis of Flow in Heterogeneous Porous Media." In J. Bear and M. Corapciogly, eds., Fundamentals of Transport Phenomena in Porous Media, Martinus Nijhoff Publ., Dordrecht, Netherlands, pp. 675-717.

Hillel, D. 1980. "Fundamentals of Soil Physics," Academic press. New York pp. 413.

Hills, R.G., P.J. Wierenga, D.B. Hudson, and M.R. Kirkland. 1991. "The Second Las Cruces Trench Experiment: Experimental Results and TwoDimensional Flow Predictions," Water Resourc. Res. 27:2707-2718.

Hudson, D.B., M.H. Young, P.J. Wierenga, and R.G. Hills. 1991. "Transient method for estimating soil water parameters of unsaturated soil cores, " Agron. Abstracts 1991. p. 221.

Jacobson, E. 1990. "Investigation of the Spatial Correlation of Saturated Hydraulic Conductivities from a Vertical Wall of a Trench, " Proceedings of the Canadian/American Conference on Hydrogeology Parameter Identification and Estimation for Aquifer and Reservoir Characterization, Sept. 18-20, Calgary, Canada.

Kirkland, M.R., R.G. Hills, and P.J. Wierenga. 1992. "Algorithms for solving Richards' Equation for variably saturated soils," Water Resourc. Res., 28:2049-2058.
Kool, J.B., J.C. Parker, and M. Th. van Genuchten. 1985. "Determining Soil Hydraulic Properties from One-step Outflow Experiments by Parameter Estimation: I. Theory and Numerical Studies," Soil Sci. Soc. Am. J. 49:1438-1354.

Kuhn, T.S. 1970. "The Structure of Scientific Revolutions," The University of Chicago Press, Chicago.

Luis, S., and D. McLaughlin. 1992. "A Stochastic Approach to Model Validation," Water Resources, 15:15-32.

Mantoglou, A., and L.W. Gelhar. 1985. "Large-Scale Models and Effective Parameters of Transient Unsaturated Flow and Contaminant Transport Using Stochastic Methods," Tech. Report 299, R.M. Parsons Lab, M.I.T., Cambridge, Massachusetts.

Mantoglou, A., and L.W. Gelhar. 1987. "Effective hydraulic conductivities of transient unsaturated flow in stratified soils," Water Resourc. Res. 23:56-68.

Mantoglou, A., and L.W. Gelhar. 1987a. "Stochastic Modeling of Large-Scale Transient Unsaturated Flow Systems," Water Resourc. Res. 23:37-46.

Mantoglou, A. and L.W. Gelhar. 1987b. "Capillary Tension Head Variance, Mean Soil Moisture Content, and Effective Specific Soil Moisture Capacity of Transient Unsaturated Flow in Stratified Soils, "Water Resourc. Res. 23:47-56.

Mantoglou, A. and L.W. Gelhar. 1987c. "Effective Hydraulic Conductivities of Transient Unsaturated Flow in Stratified Soils," Water Resourc. Res. 23:57-68.

McCord, J.T., D.B. Stephens, and J.L. Wilson. 1988. "Field-Scale Unsaturated Flow and Transport in a Sloping Uniform Porous Media: Field Experiments and Modeling Considerations," Proceedings of the International Conference and Workshop on the Validation of Flow and Transport Models for the Unsaturated Zone, Dept. of Agron. and Hort., New Mexico State University, Las Cruces, New Mexico.

Neuman, S.P. 1991. "Validation of Safety Assessment Models as a Process of Scientific and Public Confidence Building," International High Level Radioactive Waste Management Conference, Las Vegas, Nevada. 
Russo, D., and W.A. Jury. 1985. "A theoretical study of the estimation of the correlation scale in spatially variable fields 2 . Nonstationary fields," Water Resourc. Res. 23:1269-1279.

Russo, D., W.A. Jury, and G.L. Butters. 1989a. "Numerical Analysis of Solute Transport during Transient Irrigation, 1. The Effect of Hysteresis and Profile Heterogeneity," Water Resourc. Res., Vol. 25.

Russo, D., W.A. Jury, and G.L. Butters. 1989b. "Numerical Analysis of Solute Transport During Transient Irrigation, 2. The Effect of Immobile Water," Water Resourc. Res., Vol. 25.

Samper, F. J., and S.P. Neuman. 1989, "Estimation of spatial covariance structures by adjoint state maximum likelihood cross validation 1. Theory," Water Resourc. Res. 25:351-362.

Stearns, N.D. 1927. "Laboratory Tests on Physical Properties of Water-Bearing Materials," U.S. Geol. Survey, Water Supply Paper 596.

Stephens, D.B., A.M. Parsons, E.D. Mattson, K. Black, K. Flanigan, R.S. Bowman, and W.B. Cox. 1988. "A Field Experiment of Three-dimensional Flow in a Stratified Soil," Proceedings of the International Conference and Workshop on the Validation of Flow and Transport Models for the Unsaturated Zone, Dept. of Agron. and Hort., New Mexico State University, Las Cruces, New Mexico.

Stockton, J.G., and A.W. Warrick. 1971. "Spatial Variability of Unsaturated Hydraulic Conductivity," Soil Sci. Soc. Amer. Proc., Vol. 35.

Tsang, Chin-Fu. 1991. "The Modeling Process and Model Validation," Ground Water, Vol. 29, No. 6.

van Genuchten, M.Th. 1978. "Calculating the Unsaturated Hydraulic Conductivity with a New ClosedForm Analytical Model," Report 78-WR-08, Dept. of Civil Engineering, Princeton University, Princeton, New Jersey.

van Genuchten, M. Th., and P.J. Wierenga. 1986. "Determination of Solute Dispersion Coefficients," In: A Klute ed. Methods of Soil Analysis. American Society of Agronomy, Madison: 1025-1053.
Voss, C. and T.J. Nicholson., editors. 1993. "Flow and Tracer Experiments in Unsaturated Tuff and Soil," INTRAVAL, Swedish Nuclear Power Inspectorate, Stockholm.

Warrick, A.W., S.A. Musil, J.F. Artiola, D.M. Hendricks, and D.E. Myers. 1990. "Sampling. Strategies for Hydrological Properties and Chemical Constituents in the Upper Vadose Zone," Final Technical Report, USGS Grant No. 44-08-00010G1478. pp 50.

Warrick, A.W., and D.E. Myers. 1987. "Optimization of Sampling Locations for Variogram Calculations," Water Resourc. Res. 23:496-500.

Warrick, A.W., R. Zhang, M.K. El-Harris, and D.E. Myers. 1988. "Direct Comparisons Between Kriging and Other Interpolators, Proceedings of the International Conference and Workshop on the Validation of Flow and Transport Models for the Unsaturated Zone, Dept. of Agron. and Hort., New Mexico State University, Las Cruces, New Mexico.

Warrick, A.W., R. Zhang, M.M. Moody, and D.E. Myers. 1990. "Kriging Versus Alternative Interpolators: Errors and Sensitivity to Model Inputs, " In: K. Roth, H. Fluhler, W. A. Jury and J. C. Parker (ed), Field-scale water and solute flux in soils, Kirkhauser Verlag, Basel.).

Wierenga, P.J., and D. Bachelet, editors. 1988. "International Conference and Workshop on the Validation of Flow and Transport Models for the Unsaturated Zone," Dept. of Agron. and Hort., New Mexico State University, Las Cruces, NM.

Wierenga, P.J., R.G. Hills, and D.B. Hudson. 1991. "The Las Cruces Trench Site: Characterization, Experimental Results, and One-Dimensional Flow Predictions," Water Resourc. Res. 27:2695-2705.

Wierenga, P.J., D.B. Hudson, R.G. Hills, I. Porro, M.R. Kirkland and J. Vinson. 1990. "Flow and Transport at the Las Cruces Trench Site. Experiments 1 and 2." U.S. Nuclear Regulatory Commission Report. NUREG/CR-5607. pp. 413.

Wierenga, P.J., A.F. Toorman, D.B. Hudson, J. Vinson, M. Nash and R.G. Hills. 1989. "Soil Physical Properties at the Las Cruces Trench Site. " U.S. Nuclear Regulatory Commission Report. NUREG/CR-5441. pp. 91. 
Yeh, T.C. 1992, "Stochastic Modeling of

Groundwater Flow and Solute Transport in Aquifers,"

J. of Hydrological Processes, 6:369-395.

Yeh, T.C., L.W. Gelhar, and A.L. Gutjahr. 1985.

"Stochastic Analysis of Unsaturated Flow in

Heterogeneous Soils -- 3. Observations and

Applications," Water Resourc. Res., Vol. 21.

Yeh, T.C., L.W. Gelhar, and A.L. Gutjahr. 1985a. "Stochastic Analysis of Unsaturated Flow in

Heterogeneous Soils -- 1. Statistically Isotropic Media,"

Water Resourc. Res., Vol. 21.
Yeh, T.C., L.W. Gelhar, and A.L. Gutjahr. 1985 b. "Stochastic Analysis of Unisaturated Flow in Heterogeneous Soils -- 2. Statistically Anisotropic Media with Variable $\alpha$," Water Resourc. Res., Vol. 21.

Yeh, T.C., L.W. Gelhar, and P.J. Wierenga. 1986. "Observations of Spatial Variability of Soil-Water Pressure in a Field Soil," Soil Sci., Vol. 142.

Zhang, R., A.W. Warrick, and D.E. Meyers. $19>0$. Variance as a Function of Sample Support Size. Math. Geology 22:107-121. 

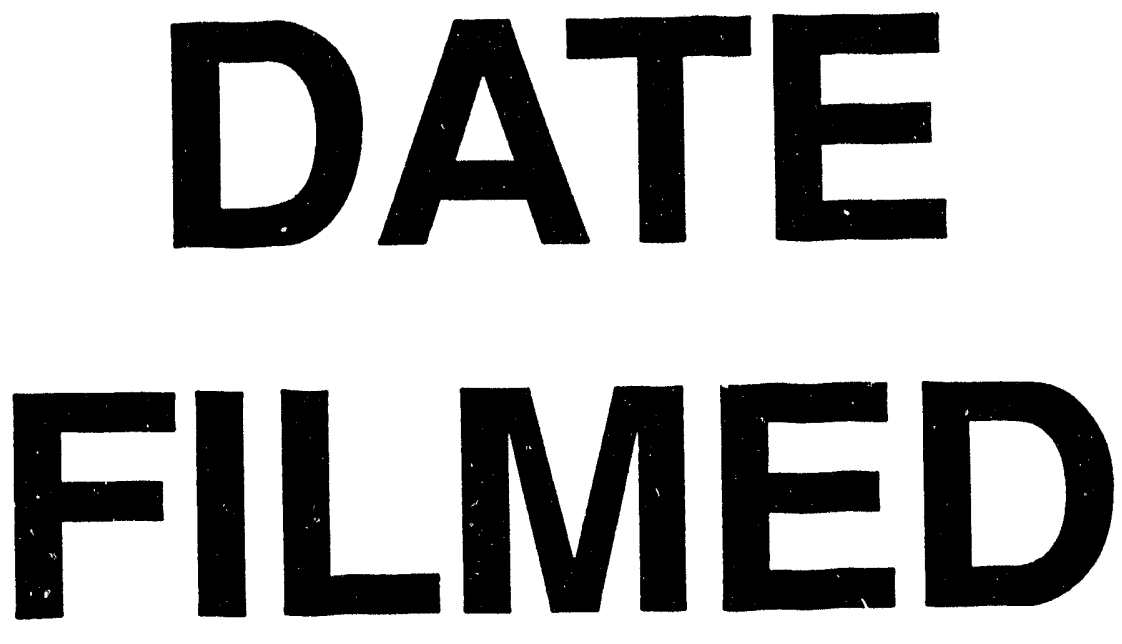

$10 / 27 / 94$
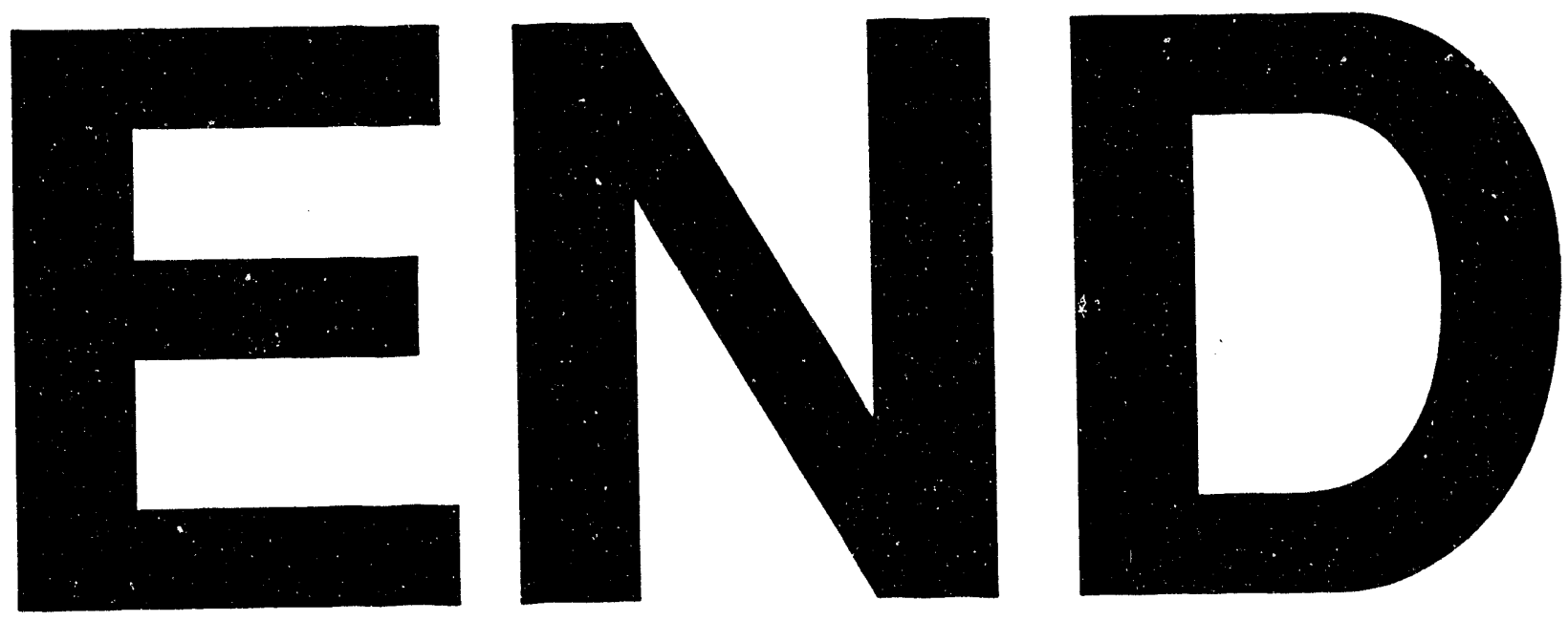


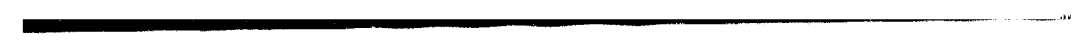

